\title{
Adopting Information and Communication Technologies for Effective Inclusive Education
}

\author{
Idorenyin Edet Johnson ${ }^{1} \quad$ Agnes Lambert Udo ${ }^{2 *}$ \\ 1.Department of Curriculum and Teaching, Faculty of Education, University of Calabar, Calabar, Cross River \\ State, Nigeria \\ 2.Department of Curriculum and Teaching, School of Education, College of Education, Afaha Nsit, Akwa Ibom \\ State, Nigeria
}

\begin{abstract}
Education had been identified and used the world over, as the most dynamic tool to achieve societal change. Over the centuries, it has been consistently used to achieve behavioural change and make man useful to himself and his society. However, it has been observed that formal education tends to exclude children and adults who have physical, emotional, intellectual, psychological, locational, linguistic and other challenges. Whereas for education to maximally achieve its objectives, it has to be inclusive. Inclusive education implies an educational system which must include disabled and gifted children, children from remote and nomadic population, street and working children, children from linguistic, ethnic, or cultural minorities as well as children and adults who are disadvantaged or marginalized. To this end, there arise a need to meet the need of every learner and ensure that no one is left out during an instructional exercise. Based on the dynamism of Information and Communication Technologies (ICTs) in education, the writers believe strongly that, if educational ICTs are appropriately adopted and effectively utilized, the challenges of inclusive education could be mitigated. This paper therefore takes a look at the definition, coverage, benefits and challenges of inclusive education. It x-rays ICTs and points out the necessary ICT tools for inclusive education. It outlines the benefits and challenges associated with the effective use of ICTs in inclusive education. Finally, the paper makes replicable recommendations for effective engagement of ICTs in inclusive education for enhanced efficiency.
\end{abstract}

Keywords: Inclusive education, Marginalized, Technological gadgets, Modern ICTs

DOI: $10.7176 / \mathrm{JEP} / 11-24-16$

Publication date:August $31^{\text {st }} 2020$

\section{Introduction}

Over time, the world over, education has been identified and used as a dynamic change agent. The level of development of a given people has always been considered to be directly proportional to their level of educational attainment. Education is the mirror of a society to the world. It is also a process by which an individual acquires life skills needed to develop and conquer his environment for a better living (Singal, 2006). Education also plays a role in differentiating individuals who are learned from those who are not in many ways. Therefore, the 1994 world conference on Special Needs Education held in Salamacana recommends that for education to maximally achieve its goals, it has to be inclusive.

Considerably, there are barriers that are inherent in the educational strategies and programs which make education insufficient, inaccessible and unaffordable to some children, youths and adults. This makes for marginalization and exclusion of some persons due to variation in culture, age, ability, place of residence and economic state. Peetsma (2001) observes that currently, the international education and social policy tends to turn towards those who are at risk of being excluded, to integrate them in the society and provide them with access to quality of basic education. This approach implies reaching out to those who are deprived of the opportunity to receive formal education due to inborne or acquired impairment, socio-economic deprivation, war, conflict or other negative factors which constitute barriers to learning (Singal, 2006).

As asserted by Singal (2008), inclusive education aims at promoting academic learning, social competence and skills, attitudinal change, and positive peer relations, thereby leading to the growth of the whole community where every member plays a valuable role. According to Lindsey (2007), the status of inclusive education in developing countries typically highlights difficulties in the implementation thereof. The author further outlines the challenges to include limited governmental support, inadequate funding, ineffective policies and legislations, insufficient manpower, political instability, economic crisis as well as ineffective and insufficient engagement of educational technologies.

Over the years, and in every field of human endeavor, the systematic application of relevant technologies has always proven dynamic in solving problems. In the field of education, engaging Information and Communication Technologies (ICTs) has altered rigidity in the way education is delivered, thereby enhancing the effectiveness and efficiency of education. Petty (2012) observes that effective technological integration can help provide all learners the ability to access the general educational curriculum, offering them multiple means to complete their tasks with so much ease, in what seemed impossible. 
The paper therefore $\mathrm{x}$-rays the definition, coverage, benefits and challenges of inclusive education as well as the definition coverage and benefits of engaging ICTs in inclusive education. Recommendations on how to appropriately engage ICTs to enhance effectiveness and efficiency in inclusive education are also proffered.

\section{Definition of Inclusive Education}

Inclusive education is seen by Candeez (2010) as an academic system that allows special education students to be included in the mainstream classes alongside their peers to ensure that everyone, irrespective of any kind of differences, has regularity of opportunity and normalization based on the philosophy of inclusion. Agreeably, Singal (2006) sees inclusive education as being concerned with the learning, participation and equal opportunities for all children, youths, and adults with specific focus on the groups vulnerable to marginalization and exclusion from society life.

Inclusive education seeks to achieve equal opportunities, effective educational programs, assistive devices, parent/guardian involvement, make students learn and appreciate each other's unique strengths, encourage students to help each other, make students with disabilities foster friendship in a natural manner and make non-disabled students get a chance to develop positive attitudes toward people with disabilities (John, 2012). Evidently, inclusive education could be seen as a kind of education that seeks to utilize available resources to ensure that education is made available to everyone, irrespective of location, age, gender culture or disability.

\section{Coverage of Inclusive Education}

According to Williams (2005) the scope of inclusive education covers all children and adults, regardless of their physical, intellectual, social, emotional, linguistic, or other conditions. It includes disabled and gifted children, street and working children, children from remote or nomadic populations, children from linguistic, ethnic or cultural minorities, and children from other disadvantaged or marginalized areas or groups.

According to UNESCO (1994) inclusive education covers the following:

i. Girls and boys who have gender issues.

i. $\quad$ Ethnic and faith minority groups, travelers, asylum seekers and refugees.

ii. Children who need support in learning the language of instruction (second language).

iii. Children with special educational needs, including those considered to have emotional, behavioral, sensory, physical or mental disabilities.

iv. Gifted and talented pupils.

v. Children with social difficulties, such as street children and prison inmates.

vi. $\quad$ People in disadvantaged, remote areas, poorly served by educational services.

vii. $\quad$ People who missed the opportunity to study in childhood.

viii. Children in need, including those in public care, orphan children.

ix. Other children, such as the ones with specific health needs, young careers, the children whose families are under stress, pregnant school girls and teenage mothers.

x. Any pupil at risk of disaffection and exclusion.

When the scope of inclusive education is effectively concerned certain benefits are evident;

\section{Benefits of Inclusive Education}

Inclusive education is beneficial to the society, parents whose children have special needs, learners with special needs, people without special needs, government and the teachers.

$i$. The society: Inclusive education is beneficial to the society by ensuring that every member of a given society is mentally and otherwise developed to participate meaningfully in the development of the society. A society is normally made up of people with different challenges and inclusive education enables all to socialize, collaborate and coexist, with the disabled not looked down upon.

ii. $\quad$ The parents whose children have special needs: In areas where inclusive education is not invoked, parents who have children with special learning needs consider such children as invalid and loss to them. Whereas with inclusive education, there is hope for such parents because they know that the educational system has room to accommodate and develop them to be useful to themselves, the parents and the society at large.

iii. $\quad$ The learners with special needs: Studies have proven that learners with special needs who learn in an inclusive environment do better in the areas of social interaction, appropriate behavior, self-esteem and language development than their counterparts in exclusive learning environment (Lindsey, 2007). Inclusive education benefits the challenged learners by addressing the functional barriers experienced by them, providing them with equitable learning opportunities and a balanced ground to experiment their different strengths, through provision of necessary support and an accessible learning environment to all (Fouxia, 2015).

iv. The teacher: To be able to communicate good, clear and meaningful lessons to learners of varying 
abilities, inclusive education places a demand on the teacher to creatively find ways of ensuring that all the learners benefit equally from every instructional exercise. The teacher also has the responsibility to creatively set learning tasks that will enable the learners with disabilities to learn with normal learners. Teachers therefore become experts in designing appropriate learning tasks and using relevant technologies.

v. The people without special learning needs: Outstandingly, learners without special learning needs tend to learn how to accommodate those that have disabilities. They develop empathy in the process of learning with the challenged learners. This quality helps them to grow up having the ability to accommodate feeble people, lend them their strengths and share in their weaknesses.

While inclusive education is beneficial to the above enumerated people, there are associated challenges that hinder effective inclusive education.

\section{Challenges to Effective Inclusive Education}

In the words of Lindsey (2007), limited governmental support, inadequate funding, ineffective policies and legislations, insufficient man-power, political instability, economic crises as well as ineffective and insufficient engagement of educational technologies are some of the challenges to inclusive education. Specifically, the following constitute challenges to effective inclusive education.

i. $\quad$ Poor funding: Everything about inclusive education centers on money. From man-power to material and technological resources needed for the smooth running of such system would require huge sum of money to acquire and maintain. The employment, training and retraining of manpower as well as the acquisition and maintenance of equipment and infrastructure needed for an effective inclusive education would also require funding. Therefore, poor funding tends to drag the wheel of inclusive education and renders it ineffective.

ii. $\quad$ Poor infrastructure: A good number of schools have very unconducive learning environment. Lack of good classrooms with proper sitting arrangement, ventilation, electricity and playgrounds contribute to crippling the effectiveness of inclusive education as infrastructure play a role in making the learning environment comfortable and conducive for all.

iii. Lack of governmental commitment: In most cases, governmental policies on inclusive education are beautifully presented on paper without a sincere commitment towards implementation. Additionally, embezzlement and misappropriation of funds also cripple governmental will towards inclusive education.

iv. $\quad$ Poor attitude of the target audience: Due to poor awareness, some persons who form the target of inclusive education programs tend to be withdrawn and unserious, thereby crippling the efforts of the exercise and frustrating the achievement of laid down objectives.

v. Insufficient teaching-learning materials: In most cases, exercise and text books as well as other materials that aid learning are limited in supply. This is more so when the said materials are given free of charge. Those who are fortunate to receive become more advantaged in learning and carrying out assigned tasks than those who don't have.

vi. Unprofessional Manpower: Some of the administrators and teachers who facilitate such programs treat it with so much levity. Such unseriousness results in lack of commitment and poor attitude towards learners and learning activities which always end in undesired resultant effects.

vii. Poor/Inexperienced Management: When the management cannot effectively channel the financial, human and material resources towards the achievement of the laid down goals and objectives of inclusive education, it becomes impossible to attain the desired heights of such instructional adventures.

viii. Poor Curriculum: Adopting a general curriculum in an inclusive education program, most times, result in poor teaching methods and ineffective instructional communication. This is because such curriculum is not tailored to suit the learning needs of the varying learners.

ix. Inappropriate and Ineffective Utilization of ICT Resources: When information and communication technologies are not systematically planned for, acquired, utilized and maintained, the entire usage may be regrettable. The inappropriate use of ICTs may imply using any of equipment or tools, software, environment and/or manpower in isolation, instead of a comprehensive use.

In view of the above problems of inclusive education, the writers strongly hold the view that ICTs could be adopted and appropriately used as effective mitigation measures.

\section{Information and Communication Technologies: The Implication}

According to Inyang-Abia (2014), ICTs are the various sets of technological tools and resources designed for creating, communicating, disseminating, storing and managing information. ICTs, therefore, cover all forms of computer, communication equipment and software, used to create, design, store, transmit, interpret and manipulate 
information in different formats, for the purpose of effectively achieving laid down educational goals and objectives (John, 2012).

ICTs in education include personal computer, Internet enabled mobile phones, laptop, Tablet, printer, scanner, transport systems, television, iPad, Closed Circuit Television (CCTV), hand magnifier, braille language technology, talking calculator, multimedia projector, paper-based pen technology, computerized speech recognition, electronic Maths sheet, abbreviation expanders, radio, network technologies and softwares. Hawkins (2010) presents features of ICT in education to include mobile learning, cloud computing, one-to-one computing, ubiquitous learning, gaming, personalized learning, redefinition of learning spaces, teacher-generated open content, smart port-folio assessment, teacher managers/monitors.

Mangal and Mangal (2012) classifies ICT in education into traditional and modern, viz:

$i$. Traditional ICTs: Printed media in the form of textbooks, resource books, journals, news items, and other literature available in the school and public libraries; verbal information and ideas exchanged with the peers, teachers, parents and other members of the society; graphical materials such as pictures, charts, maps, diagrams, posters and cartoons; 3-dimensional materials such as specimen, model, puppetry and mock-ups; audio-visual hardware equipment like, television, slide-projector, over-head projector, motion pictures, tape recorder, radio, audio-video recording devices and teaching machines.

ii. Modern ICTs: Digital video camera; multimedia personal computer (PC), laptop and notebook; application software such as word processing spreadsheets, PowerPoint, simulation and speed recognition; multi-media projector (LCD or DLP) to communicate to large groups; Local Area Network (LAN), Metropolitan Area Network (MAN) and Wide Area Network (WAN); Multimedia PC/laptop with video card and web camera or digital video camera; computer database and data processing mechanism, CD-ROM and DVD; Digital libraries; e-mail, Internet and World Wide Web (WWW); Hypermedia and hypertext resources; Computer-mediated conferencing-video and audio conferencing; Video text, teletext, Interactive Video Text, Interactive Video Disc (IVD) and Interactive Remote Instruction (IRI), and ideas of virtual classroom and virtual reality.

When used appropriately in an instructional situation, ICTs help in enhancing: effective documentation, access to education, technological literacy, remote learning resources, teacher training and creativity, individualized and group learning, effective collaboration, educational quality, basic skill acquisition, improving educational opportunities, and helping the challenged learners. To effectively achieve the benefits of instructional use of ICTs, laid down systematic procedure must be followed.

\section{Recommendations for Appropriate Adoption of ICTs in Inclusive Education}

Using ICTs to achieve an effective inclusive education would necessarily require the following:

$i$. Need Assessment/Goals and Objectives Specification: The adoption of ICTs in an inclusive learning environment must never be done haphazardly. The government or school management must carry out a proper need assessment to establish the rationale for embarking on such project. They must establish the types of learning challenges faced by individual learners. The goals and objectives in view of the project need be clearly put forward.

ii. Budget and Funding Plan: The needed equipment/infrastructure, Internet connections, man-power, power supply and every necessary accompaniment must be budgeted for. The cost of servicing and maintaining the resources must also be considered. The budget must be realistic and affordable and adequate funding should be made by the authorities concerned.

iii. Stakeholders'Briefing: While planning, the authorities concerned should endeavor to meet with the teachers, learners, parents and guardians; and get their own inputs as well, on the project. Their roles in the success of the exercise must be stressed in the light of the laid down objectives. Where there are questions or matters arising from any bias, satisfying answers should be provided.

iv. $\quad$ Prepare Effective Learning Environment: The classrooms, sitting arrangements, lighting, ventilation and power supply must be properly arranged. Good spacing must be observed between seats and there must be room for the instructor to access every learner. Arrangement of learning resources must also be carefully put in place.

v. Employment and Training of Manpower: Necessary manpower, such as teachers, content designers and developers, technicians and administrators should be employed and retrained by the concerned authorities on the effective preparation, utilization and evaluation of instructional contents using ICTs. Teachers, especially, must be trained and retrained on how to guide the learners to learn maximally using ICTs.

vi. Acquisition, Installation and Maintenance of Equipment: Every equipment earlier put forward should be acquired, installed and maintained by the concerned authorities, with the help of specialists. Also, there must be provision for alternative power supply, Internet connection as well as regular check of the equipment and replacement of malfunctioning components.

vii. $\quad$ Provision of Orientation for the Learners: Technical and other support staff in every school practicing 
inclusive education, must provide learners with necessary orientation about the usage of acquired gadgets. They must be properly shown how to safely handle equipment to derive maximum instructional benefits, while preventing damage thereof. Disciplinary measures must be put in place and taken seriously to ensure that learners are properly guided.

viii. Adapting Curriculum and Setting Learning Activities to Achieve Objectives: Curriculum developers should structure the curriculum to fit into an inclusive environment. Teachers should tailor learning activities to fit into the laid down objectives. They should use the ICTs to prepare, present and evaluate their instructional contents to a needful extent. They should inculcate the habit of staying on learning tasks in the learners while avoiding associated hazards.

ix. $\quad$ Setting Mitigation Measures to Handle Associated Hazards: There are various challenges that are either physically or psychologically associated with the instructional use of ICTs. Teachers and parents should take care of any kind of challenge that different learners may face. Challenges like fire outbreak, electric shock and accidents must be anticipated and appropriate escape measures must be put in place ahead of time.

Conclusively, it is evident that the effectiveness of education in achieving its goals and objectives of effecting the desired change in the behavior of people in the society is dependent on inclusive education which emphasizes education for all; irrespective of location, age, economic, health and physical status. However, there are challenges that must be overcome to eliminate exclusivity and ensure effective inclusive education. Going by the dynamic role of ICTs in solving problems, it is truthful to say that if appropriately utilized, ICTs would mitigate the challenges of inclusive education and ensure its effectiveness and efficiency thereof.

\section{References}

Candeez, C. N. (2010). Implications of information and communication technologies in education. Retrieved from http:/edu.issues.iict.article.12

Fouzia. K. A. (2015). Assistive technology and inclusive education. Journal of Transience, 6(2), 62-77.

Hawkins, B. C. (2010). Information and communication technologies. Retrieved from http:/mpict.org_ict_edu

Inyang-Abia, M. E. (2014). Essentials of educational technology: A handbook for educators and media practitioners. Calabar: MIFAM Services Nig. Ltd

John, S. A. (2012) Information and communication technologies: An emerging diversified trend. Port Harcourt: Galaxy Publishers.

Lindsey, G. (2007). Educational psychology and the effectiveness of inclusive education/mainstream: British Journal of Educational Psychology, 77 (1), 1-24

Mangal, S. K. \& Mangal, U. (2012). Essential of educational technology. New Delhi: PHI learning Private Limited.

Peetsma, T. (2001). Inclusion in education: Comparing pupils' development in special and regular education. Educational Review, 53(2), 125-135

Petty, R. E. (2012). Technology access in the workplace and higher education for persons with visual impairment: An examination of barriers and discussion of solutions. Independent Living Research Utilization at TIRR: Houston, Texas

Singal, N. (2006). Inclusive education in India: International concept national interpretation. International Journal of Disability, Development and Education, 52 (3), 315-269.

Singal, N. (2008). Working towards inclusion: Reflections from the classroom. Journal of Teaching and Teacher Education, 24 (6), 1516-1529.

UNESCO (1994). The Salamanca statement and framework for action on special needs education. World Conference of Special Needs Education: Access and Quality. Salamanca, Spain. Retrieved from http://www.unesco.org/education/pdf

Williams, P. (2005). Using information and communication technology with special educational needs students. The views of frontline professional. ASLIB Proceeding: New Information Perspectives, 58 (4), 330-345 